\title{
Experimental Investigations and Analysis of Thermoelectric Refrigerator with Multiple Peltier Modules
}

\author{
Harvind Yadav, Durgesh Srivastav, Gaurav Kumar, Amit Kumar Yadav, Akshay Goswami \\ B.Tech Student, Department of Mechanical Engineering, \\ ABES Engineering College, Ghaziabad, Uttar Pradesh, India
}

\begin{abstract}
How to cite this paper: Harvind Yadav | Durgesh Srivastav | Gaurav Kumar | Amit Kumar Yadav | Akshay Goswami "Experimental Investigations and Analysis of Thermoelectric Refrigerator with Multiple Peltier Modules" Published in International Journal of Trend in Scientific Research and Development (ijtsrd), ISSN: 24566470, Volume-3 | Issue-3, April 2019, pp.1337-1340, URL: https://www.ijtsrd.c om/papers/ijtsrd23 332.pdf
\end{abstract}

Copyright (C) 2019 by author(s) and International Journal of Trend in Scientific Research and Development Journal. This is an Open Access article distributed under the terms of the Creative Commons

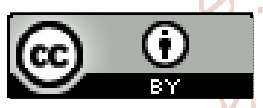
Attribution License (CC BY 4.0) (http://creativecommons.org/licenses/ by $/ 4.0$ )

\section{INTRODUCTION:}

Conventional refrigerator has been used for more than two centuries but they has certain following limitations such as-

1. Conventional refrigerators consume large amount of electrical energy which leads to more consumptions of fossil fuel in order to meet the supply which leads to production of green-house gases as well as reduces density of Earth's core.

2. Traditional refrigerant uses Freon and $\mathrm{CFC}$ as refrigerant which causes thinning of Ozone layer which leads to passing of Ultra-Violet radiation from Sun to Earth's atmosphere.

3. In traditional refrigerators there is a tendency of leakage of refrigerant which canlead to ineffective cooling and polluting atmosphere.

Thomas seebeck found that the current would flow continuously in a closed circuit made up of two dissimilar metals provided that the junctions of the metals were maintained at two different temperatures. Peltier effect was first discovered in 1834 by a French physicist Jean Charles Athanase Peltier. Peltier found opposite of Seebeck effect i.e. that the use of current at an interface between two dissimilar metals results in the absorption of heat and release of heat at subatomic level on two ends of metal joints this is a result of different energy levels in material's energy bands.

\section{THERMO-ELECTRIC COOLER:}

Peltier effect is the phenomenon to create a heat flux between the junctions of two different types of materials. Peltier module is consist of two side having opposite effect, one side gets cooler than ambient and other gets hotter. The effect is dependent upon the temperature difference between the two sides lesser the temperature difference higher will be cooling-heating effect and vice-versa.

\section{PELTIER EFFECT:}

It's a reverse of Seebeck effect which describes when the two dissimilar metals are brought in contact a voltage difference is established opposite to Seebeck effect inPeltier effect when voltage is applied to Peltier the temperature difference gets built since it has heating and cooling effect simultaneously it can be utilized for cooling or heating or both simultaneously. 


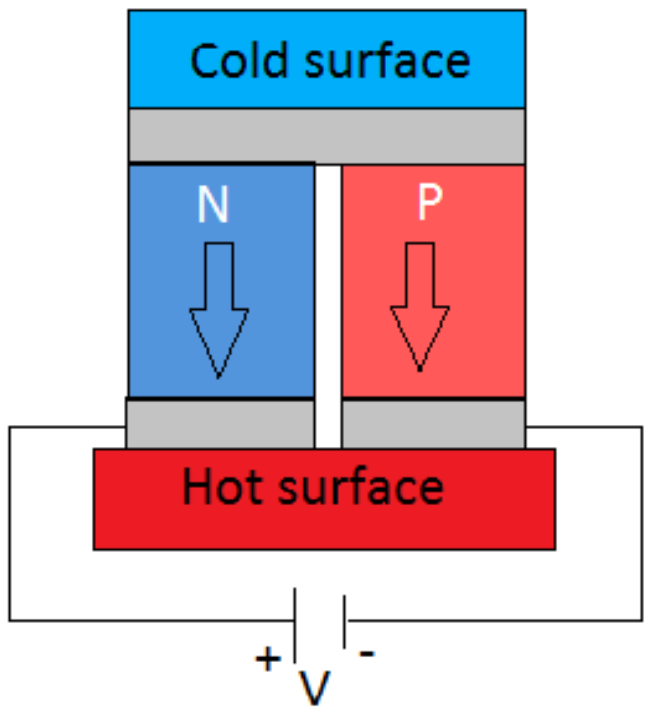

Fig. 1: Peltier Effect

\section{WORKING PRINCIPLE:}

Mainly in thermoelectric module a two dissimilar conductors are semiconductors as they can be doped and hence high carrier charge can be achieved commonly Bismuth telluride is used. As in fig. 1 if the module is in reverse bias then the electron from $\mathrm{P}$ side will move towards $\mathrm{N}$ type semiconductor which means electron will move to high energy state thus absorbing heat from surrounding and on the other hand electron from $\mathrm{N}$ type semiconductor will move to positive terminal which will cause electron to jump in lower energy state thus releasing heat in surrounding.

Multiple couples are connected electrically in series and thermally in parallel the couples are separated from one another by ceramic.

The performance of Peltier module is greatly affected by the temperature difference between the two sides, to achieve very low temperature on cold side the hot side must be as cool as possible by means of heat sinks or other cooling systems.

\section{METHODOLOGY:}

To conduct experiment Cold side of Peltier consisting fan for fast cooling of chamber isfitted inside the chamber and hot side Heat sink have exhaust to surrounding, for measuring real time temperature of cold side a digital thermometer is fitted inside the cooling chamber.

\section{Abbreviations -}

$\alpha \quad=$ Seebeck coefficient

$\mathrm{K}_{\mathrm{m}}=$ Peltier electrical conductance

$\mathrm{R}_{\mathrm{m}}=$ Peltier electrical resistance

$\mathrm{Q}_{\mathrm{C}}=$ Heat absorbed at cold side of Peltier

$\mathrm{Q}_{\mathrm{h}}=$ Heat rejected at hot side of Peltier

$\mathrm{T}_{\mathrm{h}}=$ Initial temperature of cooling chamber

$\mathrm{T}_{\mathrm{c}}=$ Final temperature of cooling chamber

$\mathrm{V}_{\text {max }}=$ Peltier maximum voltage rating

$\mathrm{I}_{\max }=$ Peltier maximum current rating

Equations for Peltier coefficients-

$\alpha=V_{\max } \div T_{h}$

$\mathrm{R}_{\mathrm{m}}=\left(\left(\mathrm{T}_{\mathrm{h}}-\Delta \mathrm{T}_{\max }\right) \times \mathrm{V}_{\max }\right) \div\left(\mathrm{T}_{\mathrm{h}} \times \mathrm{I}_{\max }\right)$

$\mathrm{K}_{\mathrm{m}}=\left(\left(\mathrm{T}_{\mathrm{h}}-\Delta \mathrm{T}_{\max }\right)\left(\mathrm{V}_{\max } \times \mathrm{I}_{\max }\right)\right) \div\left(2 \Delta \mathrm{T}_{\max } \times \mathrm{T}_{\mathrm{h}}\right)$
For measuring heat absorbed at cold side and heat rejected on hot side the following equations have been used-

Heat absorbed at cold side (RE)-

$\mathrm{Q}_{\mathrm{c}}=\left(\alpha \times \mathrm{I} \times \mathrm{T}_{\mathrm{c}}\right)-\left(\left(\mathrm{I}^{2} \times \mathrm{R}_{\mathrm{m}}\right) \div 2\right)-\left(\mathrm{K}_{\mathrm{m}}\left(\mathrm{T}_{\mathrm{h}}-\mathrm{T}_{\mathrm{c}}\right)\right)$

Heat rejected at hot side-

$\mathrm{Q}_{\mathrm{h}}=\left(\alpha \times \mathrm{I} \times \mathrm{T}_{\mathrm{h}}\right)+\left(\left(\mathrm{I}^{2} \times \mathrm{R}_{\mathrm{m}}\right) \div 2\right)-\left(\mathrm{K}_{\mathrm{m}}\left(\mathrm{T}_{\mathrm{h}}-\mathrm{T}_{\mathrm{c}}\right)\right)$

Work input-

$\mathrm{W}=\mathrm{Q}_{\mathrm{h}}-\mathrm{Q}_{\mathrm{c}}$

\section{COMPONENTS USED IN EXPERIMENTAL SETUP:}

A. PELTIER MODULE:

The Peltier module used is TEC1-12706 as its operating conditions are feasible and it has moderate resistance and power input.

\section{T E C1 - 12706

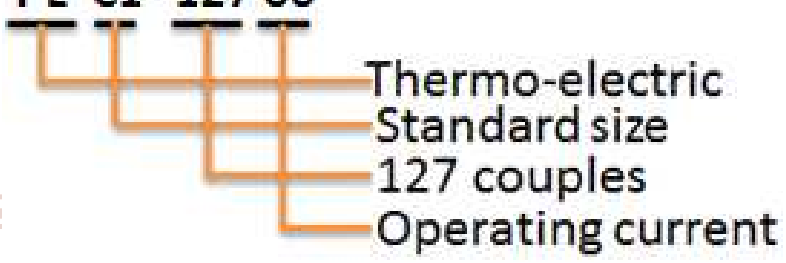

Fig. 2: Nomenclature of Peltier module

\section{(I)

(o)

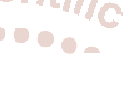

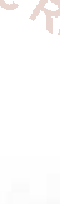

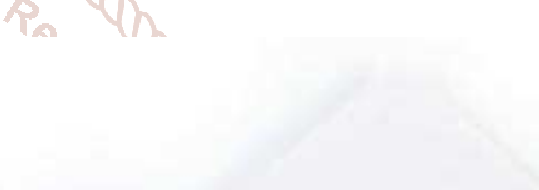

\section{in}

\section{(n)}
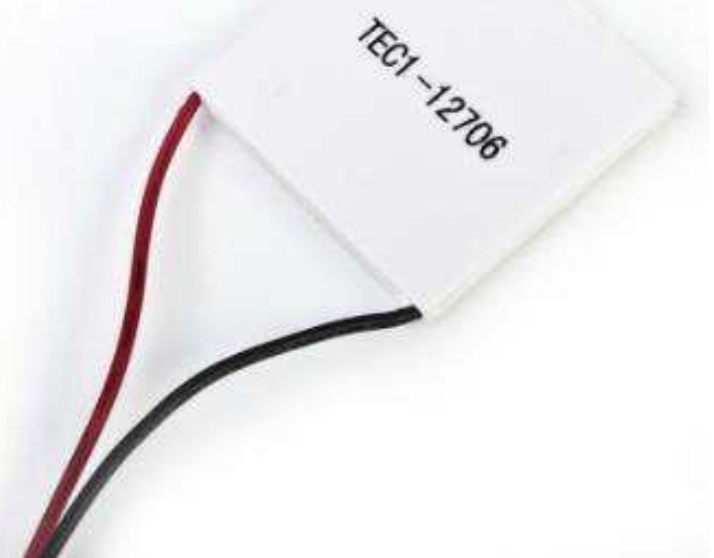

Fig. 3: Peltier module Specifications of TEC1-12706

Size $40 \times 40 \times 3.9$ cubic mm, Weight $27 \mathrm{~g}$ $\mathrm{I}_{\max }$ 6.4Amp, $\mathrm{V}_{\max } 14.4 \mathrm{~V}, \mathrm{R}_{\mathrm{m}} 1.98$ Ohms Max temperature difference 68

$Q_{\max }$ (initially) 63 Watts

\section{B. SMPS (SWITCHED MODE POWER SUPPLY):}

The electronic power supply integrated with the switching regulator for converting AC supply into DC efficiently and consistently with desired output, called as switched mode power supply. It is used to achieve regulated DC output voltage from unregulated AC input source.

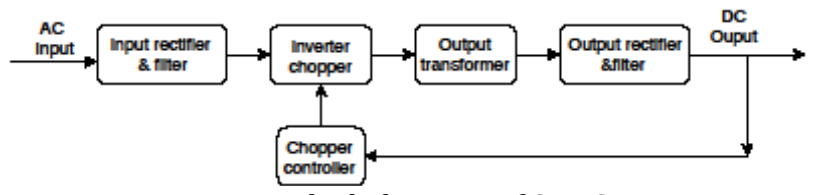

Fig.4: Block diagram of SMPS 


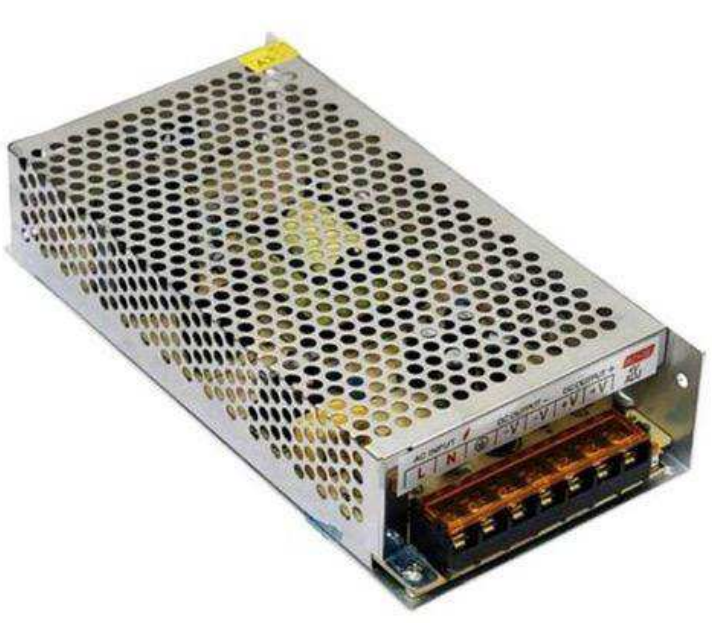

Fig. 5: SMPS

Specification of SMPS-

$\begin{array}{ll}\text { Input Voltage } & : 100-270 \mathrm{~V} \mathrm{AC} \\ \text { Output Voltage } & : 12 \mathrm{~V} \mathrm{DC} \\ \text { Output Current } & : 10 \mathrm{Amp} \\ \text { Power Factor } & : 0.95 \\ \text { Frequency Range } & : 47-67 \mathrm{~Hz}\end{array}$

\section{SUPPLY REGULATOR:}

A supply regulator is device which is used in order to get steady, reliable output supply.

It acts as supply check for Peltier in order to prevent any overloading from abruption in supply and it also facilitates in providing a range of output supply within the max rating limit to perform experiments.

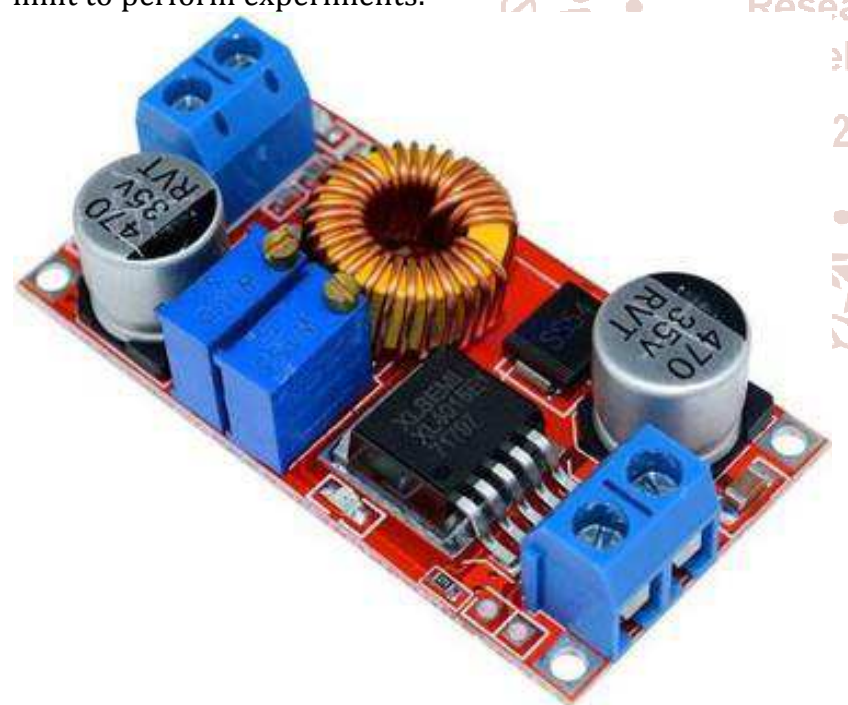

Fig. 6: Supply convertor

Specifications-

Output Voltage : $0.1-12 \mathrm{~V}$ DC

Output Current : 0.1-5Amp

\section{HEAT SINK:}

It is an integral part of thermo-electric refrigerator which necessary for two reasons-

A. To remove the heat of hot side of Peltier to atmosphere.

B. To properly circulate the medium inside the cooling chamber to ensure fast response within the cooling chamber.

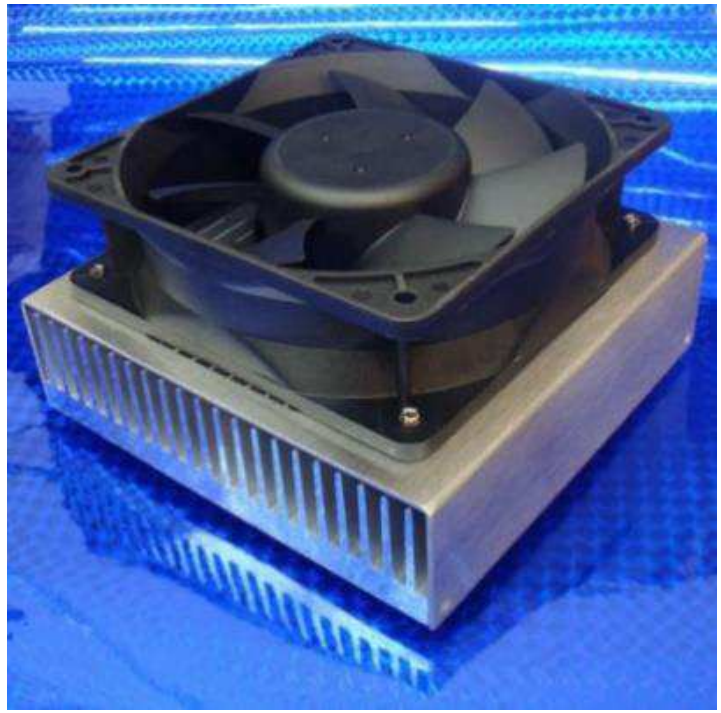

Fig. 7: Heat sink

E. DIGITAL THERMOMETER:

Digital thermometers are fast, accurate and easily portable they have permanent probe attached to it. The response time depends upon the type of sensor used it can be thermocouple type, resistance type, or thermistor type. We have used PM 10 model digital thermometer.

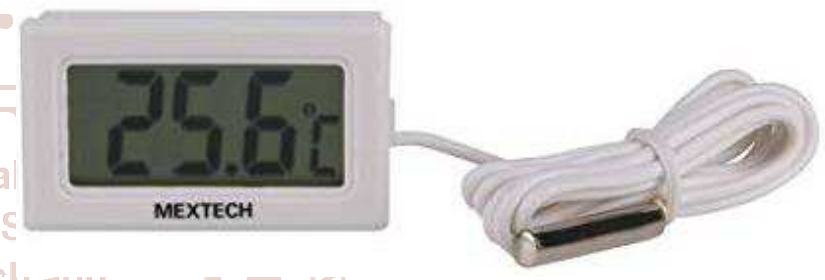

Fig. 8: Digital thermometer

\section{EXPERIMENTAL SETUP:}

Experimental setup is made of ply-wood (thermal conductivity: $0.13 \mathrm{~W} / \mathrm{m}-\mathrm{K}$ at 25 degrees Celsius) and for - insulation we have used the polystyrene foam (thermal conductivity: $0.033 \mathrm{~W} / \mathrm{m}-\mathrm{K}$ at STP).

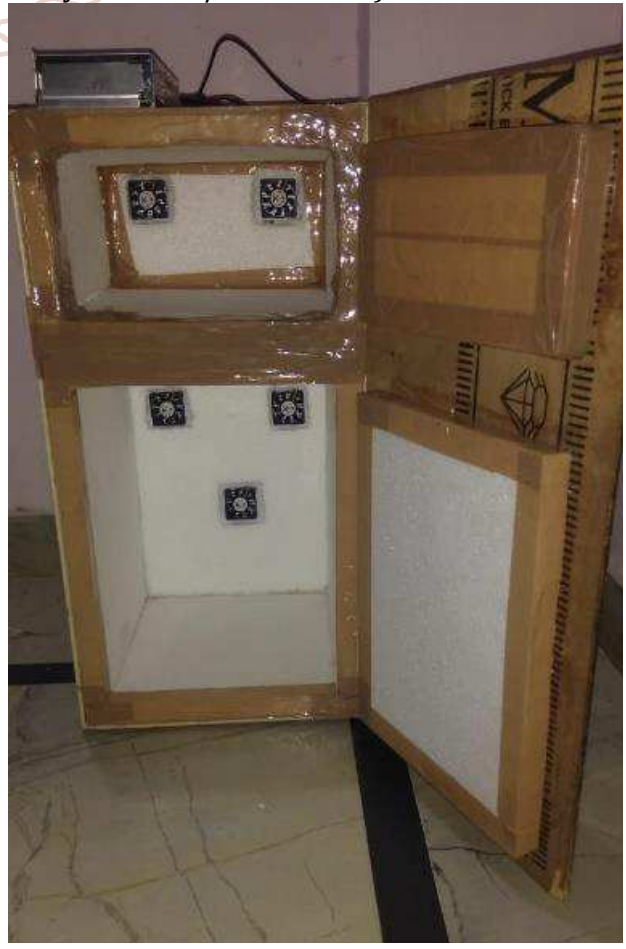

Fig. 9: Prototype (front view) 
The prototype has two separate compartments, upper chamber has two Peltier module and lower chamber has three Peltier module.

\section{Cooling space-}

Upper chamber : 240x270x140cubic mm Lower chamber : 240x270x330cubic mm

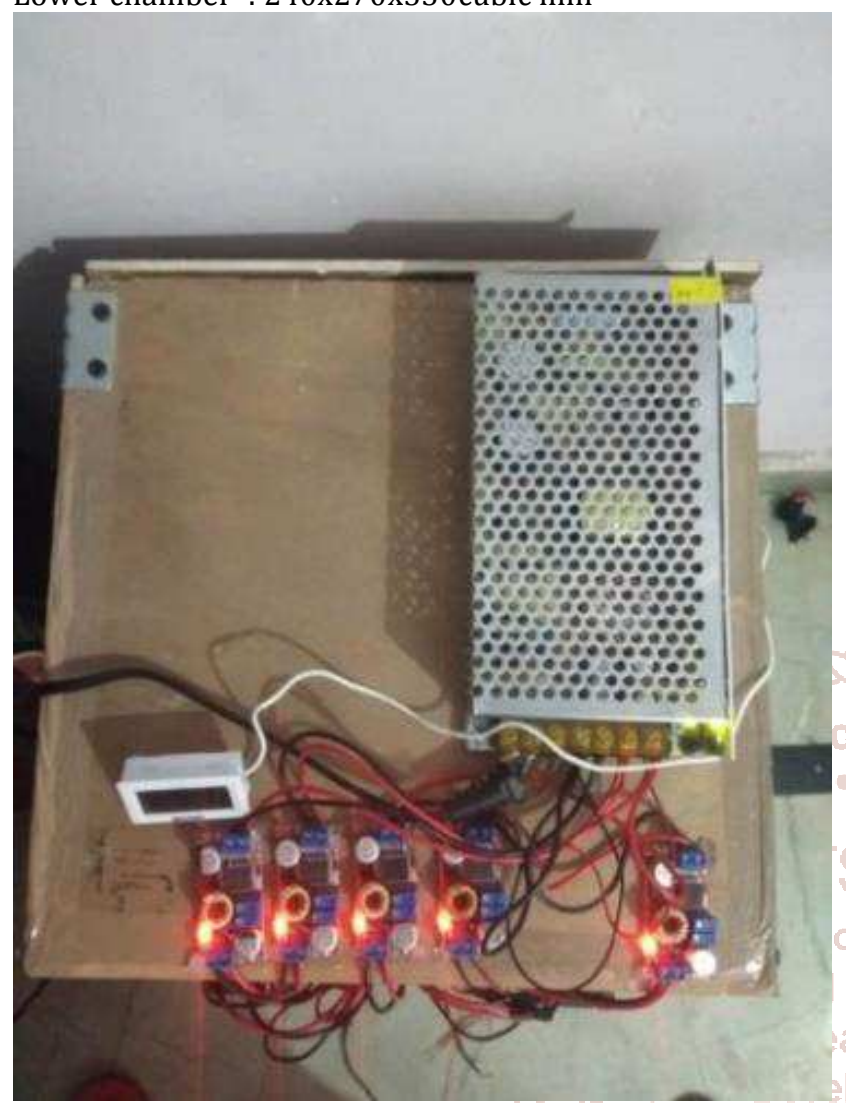

Fig. 10: Prototype (top view)

Peltier operating conditionsInput voltage : $6 \mathrm{~V} \mathrm{DC}$ Input current : $3 \mathrm{Amp} \mathrm{DC}$

\section{RESULTS AND DISCUSSION:}

Graph between temperatures of cooling space versus time has been shown below-

Graph no. 1: In upper chamber

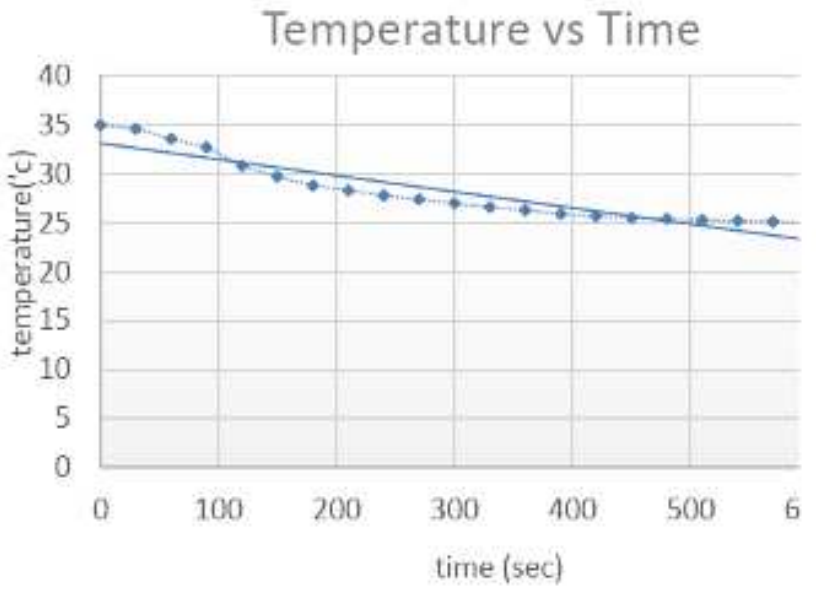

Graph 1: Temperature vs Time graph of upper

In above graph, Two Peltier shows the temperature drop from 35 to 25 degrees Celsius over a time period of $10 \mathrm{~min}$ in upper chamber (240x270x140 cubic mm i.e. 9.07L).
Graph no.2: In lower chamber

\section{Temperature vs Time}

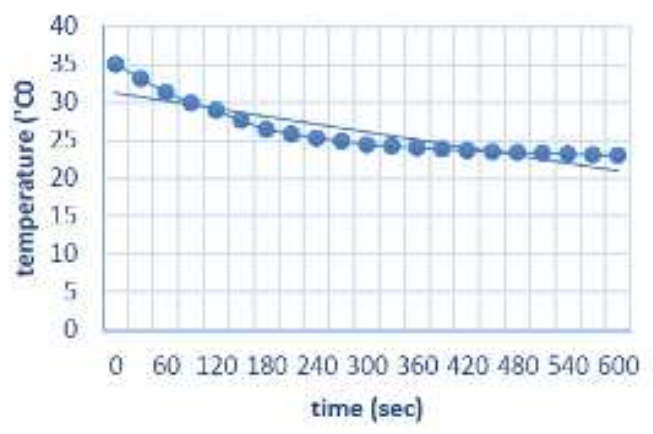

Graph 2: Temperature vs Time graph of lower

In above graph, Three Peltier shows the temperature drop from 35 to 23 degrees Celsius over a time period of $10 \mathrm{~min}$ in lower chamber (240x270x330 i.e. 21.38L).

This shows the power increases significantly with an increase in no. of Peltiers module with heat sinks.

\section{CONCLUSION AND FUTURE SCOPE:}

The study of Thermo-electric refrigerator has been done successfully and the drop in temperature of 10 and 12 degrees has been observed in upper and lower chambers respectively in 10 minutes.

In context of its future scope, the performance of this scale refrigerator can be improved significantly by using efficient liquid cooling to lower the hot side temperature as low as possible.

The hot side exhaust can also be used as a hot blower.

\section{REFERENCES:}

[1] Manoj Kumar Rawat, Himadr Chattopadhya \& Subhasis Neogi, Volume 3, Pages 362-367, 2013, "A review on development of thermoelectric refrigeration and air conditioning system: A novel potential green refrigeration and air conditioning technology",22502459.

[2] Sujit G, Antony Varghese, Ashish Achankunju, Renchi George \& Vishnu V, Volume 2, Pages 373-379, 2016, "Design and fabrication of thermoelectric refrigerator with thermosiphonsystem",2395-3470.

[3] Dongare V.K, Kinare R.V, Parkar M.H \&Salunke R.P, Volume 5, Pages 2970-2974, 2018, "Design and development of thermoelectric refrigerator", e-2395-0056,p-2395-0072.

[4] Prof. Rajendra. P. Patil, Pradhyumna Suryawanshi, Akshay Pawar \& Avdhoot Pawar, Pages 614-618, 2017, "Thermoelectricrefrigeration using Peltier effect", 2277-9655.

[5] Rakesh B.K., Anuj Shayam, Mithun Sharma. M.N., Mohan. M. \& Vinay Karthik, Volume 1, Pages332338“Study, Analysisand Fabrication of thermoelectric cooling system", 2455-2631.

[6] Benziger B, Anu nair P \& Balakrishnan P, Volume 4, Pages 49-56 2015, "Review paper onthermoelectricairconditionerusing Peltiermodules", 2319-2259.

[7] Thakkar Mohit Pravinchandra, "A report onPeltier cooling module".

[8] Pooja Iyer Mani, "A thesis on Design,Modeling and simulation of a thermoelectric cooling system (TEC)". 